\title{
Genetic characterization of Gac (Momordica cochinchinesis) accessions in Southern Vietnam by ISSR markers
}

\author{
VIET THE HO^, HUU TRIET LE, THANH AN NGUYEN \\ Ho Chi Minh City University of Food Industry. 140 Le Trong Tan Street, Tan Phu district, Ho Chi Minh City, Vietnam. \\ Tel: +84.933-025-523, `email: thehv@hufi.edu.vn, thehv@ cntp.edu.vn
}

Manuscript received: 24 December 2018. Revision accepted: 17 January 2019.

\begin{abstract}
Ho VT, Le HT, Nguyen TA. 2019. Genetic characterization of Gac (Momordica cochinchinesis) accessions in Southern Vietnam by ISSR markers. Biodiversitas 20: 387-392. Gac (Momordica cochinchinesis) plays important roles in Vietnamese cuisine and medicine. It has high nutrient and medicinal values. Demand of gac fruit as ingredient for food processing and raw material for health industry requires accelerated gac cultivation. However, gac quality is variable due to the uncertain available germplasm and its management as breeding stock. Identification of gac cultivars and landraces in Vietnam is mainly based on personal experience relying on morphological traits, thus the conservation and breeding have low impact on productivity and quality of product. Recently, the development of molecular markers has been useful in identifying specific plant(s). In this study, genetic richness and relativeness of 14 gac accessions collected from different provinces in Southern Vietnam were evaluated by using 10 Inter-Simple Sequence Repeats (ISSR) markers. Results revealed large variation in genetic background of studied gac accessions. Seven DNA-based markers with potential to differentiate gac genotypes were recorded. The results provide molecular biological information for classification, identification plant origins, breeding and conserving programs of gac in Vietnam.
\end{abstract}

Keywords Gac, genetic diversity, ISSR, molecular markers, Momordica cochinchinesis

\section{INTRODUCTION}

Gac (Momordica cochinchinesis) is a herbaceous plant popularly grown in Vietnam. Fruits of this plant are used as material in food processing (Ishida et al. 2004). Glutinous rice cooked with gac fruit (xoi gac) is popular and favorite dish which is used on wedding, birthday and New Year parties. Young gac fruits and shoots are also used as food materials in Thai cuisine (Kubola and Siriamornpun 2011). Gac fruits are important ingredient in traditional medicine. Studies have revealed the high-value compounds, such as lycopene and $\beta$-carotene (Vuong et al. 2002), vitamin E (Vuong and King 2003), and high amount of antioxidant with good bioavailability (Burke et al. 2005) in the gac fruits. The gac fruits are valuable for anti-inflammatory (Kha et al. 2012) and anticancer activities (Tien et al. 2005; Zheng et al. 2014), reducing cardiovascular disease (Bazzano et al. 2002). Gac seeds are also important in Vietnam and Chinese medicine (Kubola and Siriamornpun 2011). In order to meet the increasing demand of the market as raw materials for cooking, natural colorant industry, food additive, and functional food, the growing area of gac in Vietnam are expanding lately. However, there is not adequate research on this species due to lack of information on genetic characteristics (Nguyen et al. 2014, Pham et al. 2017).

In recent years, scientists have been approaching closer to adopt DNA markers in evaluating genetic potential as well as the selection of gac in Vietnam. In the central region, Nguyen and her colleagues used molecular biology techniques to select gac genotypes (Nguyen et al. 2014).
More recently, Pham and colleagues also assessed the genetic diversity of the gac collection from the Mekong Delta (Pham et al. 2017). However, these two studies mainly employed RAPD (Random Amplification of Polymorphic DNA) technique which is a simple, easy to implement technique and does not require genetic information for the subject. Nevertheless, this marker shows a low repeatability score and results in a high degree of reliance on reactive conditions such as DNA concentrations, the concentration of the components in the PCR reaction, the number of cycles of the reaction (Williams et al. 1990; Mbwana et al. 2006).

Recently, the Inter-Simple Sequence Repeat (ISSR) technique has been focused on the genetic diversity of many plant species such as rice, wheat, millet, grapes, sweet potatoes, apples and Momordica dioica (Reddy et al. 2002; Singh et al. 2015; Choudhary et al. 201; Shukla et al. 2017). Because it could eliminate RAPD limitations, leading the expansion of using ISSR in genetic diversity research, population genetic studies, genetic markers, genetic markers, crop identification, source analysis, identification, genetic change identification, and crossbreeding (Nguyen 2014). In this study, total of 10 ISSR primers was used to evaluate the genetic diversity of 14 gac samples in Southern provinces of Vietnam. The obtained results could provide scientific information for identification, classification, propagation, and production of gac in the area. 


\section{MATERIALS AND METHODS}

\section{Sample collection}

Total of 14 gac genotypes was collected from different provinces in Southern Vietnam (Figure 1 and Table 1). After harvesting, leaf samples were dried in silica gel and stored until use.
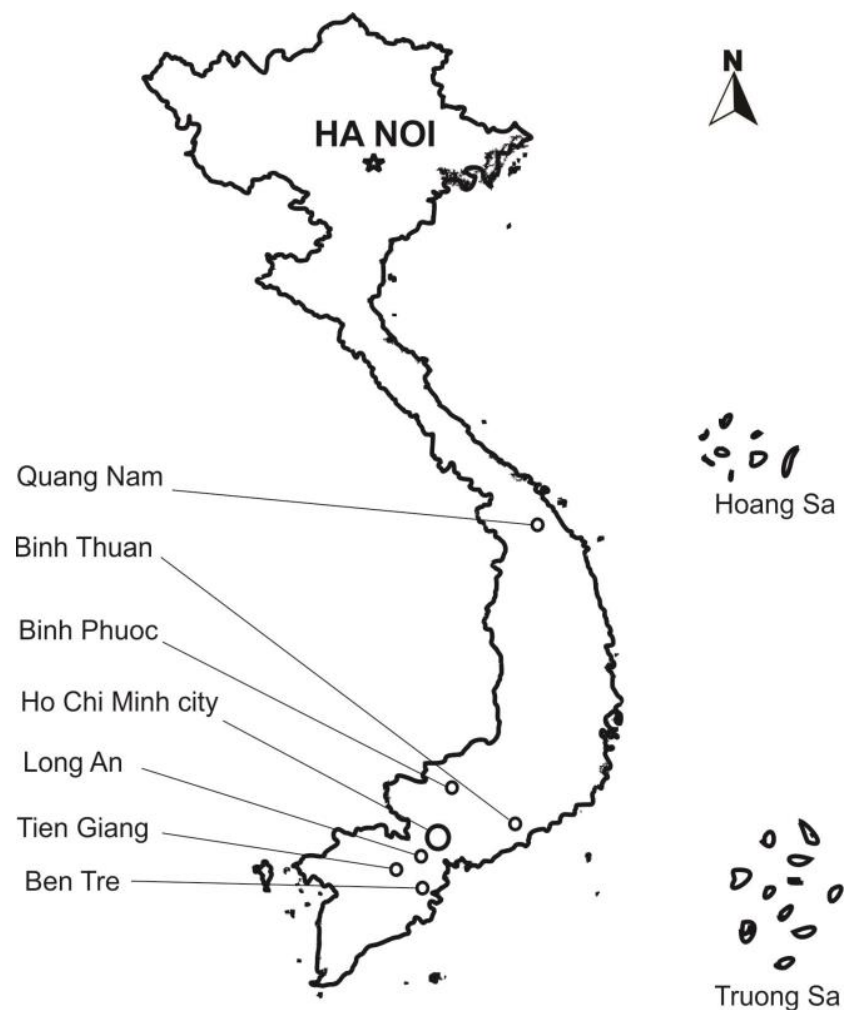

Figure 1. Targeted areas for collecting gac genotypes in Southern Vietnam

Table 1. Gac samples collected for genetic characterization in the present study

\begin{tabular}{lll}
\hline No. & Collected location & $\begin{array}{l}\text { Sample } \\
\text { code }\end{array}$ \\
\hline 1 & Chau Thanh, Tien Giang province & G1 \\
2 & Cai Be, Tien Giang province & G2 \\
3 & Cai Be, Tien Giang province & G3 \\
4 & Bu Dang, Binh Phuoc province & G4 \\
5 & Bu Dang, Binh Phuoc province & G5 \\
6 & Quang Nam province & G6 \\
7 & Mo Cay, Ben Tre province & G7 \\
8 & Ham Thuan Nam, Binh Thuan province & G8 \\
9 & Thang Binh, Quang Nam province & G9 \\
10 & Thang Binh, Quang Nam province & G10 \\
11 & Ho Chi Minh city & G11 \\
12 & Ben Tre province & G12 \\
13 & Duc Hoa, Long An province & G13 \\
14 & Ben Tre province & G14 \\
\hline
\end{tabular}

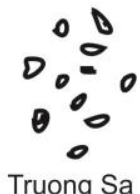

\section{DNA extraction}

Total DNA was extracted from dried gac leaves as follows: $0.1 \mathrm{~g}$ of gac leaves was ground into fine powder with liquid nitrogen using porcelain pestle and added $1 \mathrm{~mL}$ of extraction buffer containing sodium bisulfite $4 \%$. The samples were then transferred to a $2 \mathrm{~mL}$ Eppendorf tube and well vortexed, continued adding $250 \mu \mathrm{L}$ of $10 \%$ SDS solution and incubated at $65^{\circ} \mathrm{C}$ for 1 hour. Then, amount of $600 \mu \mathrm{L}$ of chloroform: isoamyl alcohol (ratio 24: 1) was added and lightly converted to mix for 1 minute. The sample was next centrifuged $12,000 \mathrm{rpm}$ at $4^{\circ} \mathrm{C}$ for 10 minutes. The supernatant solution was transferred into a new $2 \mathrm{~mL}$ Eppendorf tube. A 1: 1 volume of isopropanol was added, refrigerated for 1 hour at $-20^{\circ} \mathrm{C}$ and centrifuged at $12,000 \mathrm{rpm}$ at $4{ }^{\circ} \mathrm{C}$ for 10 minutes. Next, the upper fluid was removed and the pellet was harvested. Amount of 300 $\mu \mathrm{L}$ of $70 \%$ ethanol was used to clean the pellet by centrifuging at $8,000 \mathrm{rpm}$ in $4^{\circ} \mathrm{C}$ for 5 minutes. Ethanol was removed and pellet was dried in air. Finally, $100 \mu \mathrm{L}$ TE $1 \mathrm{X}$ was added and DNA quality was then tested by electrophoresis on $1 \%$ agarose gel in TAE $1 \mathrm{X}$ buffer and stained with Gelred dye (Biotium, USA). The result was observed under ultraviolet light by Quantum-ST4 3000 gel reader (Montreal-Biotech, Canada). DNA concentrations were determined by spectrophotometer (Optima SP 3000 nano UV-VIS, Japan) and the DNA sample was stored at$20{ }^{\circ} \mathrm{C}$ until use.

\section{ISSR reaction}

In this study, total of 10 ISSR primers was used to study genetic diversity of gac genotypes (Behera et al. 2007; Shukla et al. 2017). The sequences of primers are shown in Table 2.

The composition of PCR reactions were performed as follows: $7.5 \mu \mathrm{L} 2 \mathrm{X}$ Mytaq Red Mix (Bioline, UK), $30 \mathrm{ng}$ DNA, $0.2 \mu \mathrm{M}$ primer and PCR for final volume of $15 \mu \mathrm{L}$. The reaction conditions were as follows: initial denaturation at $95^{\circ} \mathrm{C}$ for 2 minutes; then 35 cycles of 30 seconds at $95^{\circ} \mathrm{C}, 30$ seconds at $35^{\circ} \mathrm{C}$, and 54 seconds at $72^{\circ} \mathrm{C}$ and $5 \mathrm{~min}$ finish at $72^{\circ} \mathrm{C}$ with the SureCycler 8800 Thermal Cycler (Agilent, USA). PCR amplification was then separated by electrophoresis in $1.5 \%$ agarose gel in $1 \mathrm{X}$ TAE buffer, and stained with $0.5 \mu \mathrm{g} / \mathrm{mL}$ Gelred TM loading buffer then visualized under ultraviolet light.

Table 2. List of 10 ISSR primers to analyze genetic diversity of 14 gac genotypes in Southern Vietnam

\begin{tabular}{ll}
\hline Primer & Primer sequence \\
\hline UBC880 & GGAGAGGAGAGGAGA \\
UBC825 & ACACACACACACACACT \\
UBC841 & GAGAGAGAGAGAGAGACTC \\
UBC855 & ACACACACACACACACCTT \\
UBC813 & CTCTCTCTCTCTCTCTT \\
UBC853 & TCTCTCTCTCTCTCTCRT \\
UBC809 & AGAGAGAGAGAGAGAGG \\
UBC814 & CTCTCTCTCTCTCTCTA \\
UBC811 & GAGAGAGAGAGAGAGAC \\
UBC810 & GAGAGAGAGAGAGAGAT \\
\hline
\end{tabular}




\section{Data analysis}

After electrophoresis of PCR reactions, clear amplification bands were used in the analysis. Only reproducible bands in two PCR replicates were considered for analyzed, the weak signal bands were excluded from final analysis. Since ISSR is a dominant marker, at each locus, the presence of amplified band was interpreted as either a heterozygote or dominant homozygote and the absence of a band in corresponding position as recessive homozygote (Debnath et al. 2008). Clearly visible ISSR amplified bands were scored as 1 , whereas the absent band was scored as 0 . The numbers of scored bands (SB), number of polymorphic bands (NPB) and percentage of polymorphic bands (PPB) were obtained. The quality information of the primers is determined by the PIC (Polymorphism Information Content) according to the formula of Chesnokov and Artemyeva (2015).

$$
\mathrm{PIC}_{\mathrm{j}}=1-\sum_{\mathrm{i}=1}^{n} \mathrm{Pi}
$$

Where, $i$ is the $i$ th line of the primer $j, n$ is the number of bands of the primer $\mathrm{j}, \mathrm{P}$ is the frequency of the band.

The ability of primers to differentiate between genotypes was evaluated by their resolving power (RP) value as describe by Prevost and Wilkinon (1999).

$$
\mathrm{RP}=\sum_{i=1}^{n} \mathrm{BI} i
$$

Where, $\mathrm{n}$ is the NPB of that primer and $\mathrm{BI}_{i}$ (Informativeness of a band) $=1-(2 x|0.5-p|), \mathrm{p}$ is the proportion of the 14 gac genotypes containing the band, IB value was calculated for 10 ISSR primers.

Phylogeny is built based on the Unweighted Pair Group Method with the Arithmetic mean (UPGMA) and the algorithm with the SAHN module in NTSYSpc 2.1 (Rohlf 2000). Principal Coordinate Analysis (PCO) was performed based on RAPD data to have better understanding about similarity among accessions by using PCO package in NTSYS-pc 2.1 (Ibrahim et al. 2017).

\section{RESULTS AND DISCUSSION}

Totally, 14 gac genotypes were characterized with 10 ISSR primers. The obtained results showed that the bands appeared clearly on $1.5 \%$ agarose gel (Figure 2, Figure 3, and Figure 4). The tested primers generated from 3 to 12 amplifications per reaction and the length of amplification varies approximately from 150 to $2,000 \mathrm{bp}$. Our results are consistent with study of Pham and colleagues in 2017, where the genetic correlation of 20 gac samples was characterized by using 10 RAPD primers and resulting 126 bands; however the amplified bands in this study is relatively higher than study of Choudhary and colleagues when they used ISSR to evaluate the genetic homogeneity of different Momordica dioica plants with 2-4 bands per primer (Pham et al. 2017; Choudhary et al. 2017). Among those, there were 114 polymorph bands, and an average of 11.4 bands per primer. We also found that all primers were suitable for the study of gac through the number of amplified and high polymorphic bands as well as other parameters of primers (Table 3). All primers showed high PIC values from 0.60 to 0.90 . This means that all of these primers are suitable for studying genetic diversity in gac since according to Botstein et al. (1980): Primer for very high PIC if $\geq 0.5$; Primer for relative information if $0.5>$ $\mathrm{PIC} \geq 0.25$ and little information if PIC $<0.25$. The resolving power (RP) index was also to assess the ability to differentiate gac genotypes. The RP value varied from 4.57 for primer UBC855 to 8.57 for primer UBC813. In general, the primers showing higher RP value could distinguish more genotypes and shower higher polymorphic bands (Debnath et al. 2008).

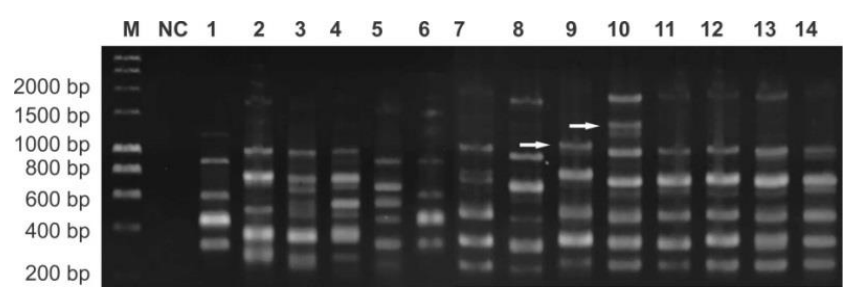

Figure 2. Representative ISSR result with UBC811 primer. (The arrow shows the candidate amplification marker to distinguish specific gac genotype. The number is corresponding to sample number in Table 1; M: DNA marker; NC: Negative control without DNA)

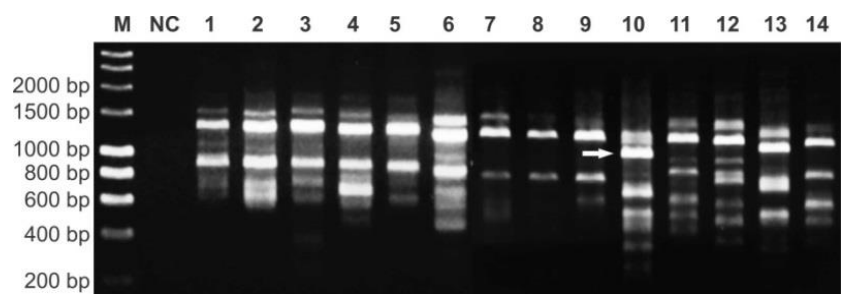

Figure 3. Representative ISSR result with UBC853 primer. (The arrow shows the candidate amplification marker to distinguish specific gac genotype. The number is corresponding to sample number in Table 1; M: DNA marker; NC: Negative control without DNA)

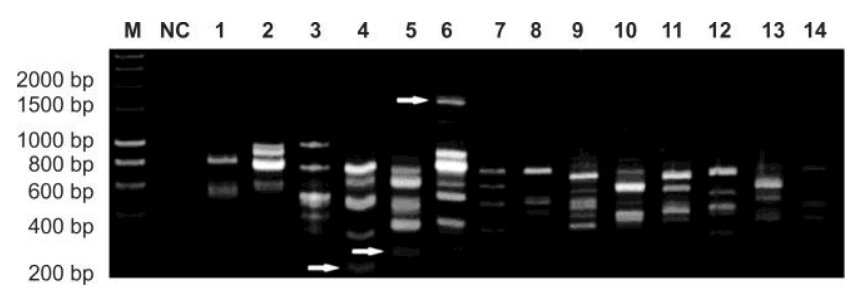

Figure 4. Representative ISSR result with UBC841 primer. (The arrow shows the candidate amplification marker to distinguish specific gac genotype. The number is corresponding to sample number in Table 1; M: DNA marker; NC: Negative control without DNA) 
The ability to create multiple polymorphisms of ISSR primers is important in the analysis of genetic diversity as they provide a large amount of information on the genetic structure of the analytical individuals. Out of a total of 126 amplified DNA bands, up to 66 polymorphic DNA bands accounted for $66.2 \%$ with an average of 6.6 polymorphic bands appearing on each primer. This finding is consistent with previous study of Rahimi and colleagues when using the same ISSR primer set and found the polymorphism of $69.91 \%$ in different ecotypes of sand plantain (Rahimi et al. 2017). This data also demonstrates that the primers used in the study are capable of amplifying in highly genetically distinct regions between gac samples. However, the obtained polymorphism of $66.2 \%$ in this study is lower in comparison to previous studies conducted by RAPD markers: such as $90.4 \%$ in Pham et al. (2017), 99.43\% in Bootprom et al. (2012) and $100 \%$ in study conducted by ISSR markers (Wimalasiri et al. 2016). The lower polymorphism of ISSR makers in the comparison with RAPD markers was also previously reported by Indian research group when they characterized genetic composition of Solanum L. species (Anil Kumar et al. 2018).

The combination of amplified bands in this study demonstrates the high potential of ISSR primers in identifying gac genotypes. Based on obtained ISSR data, specific gac genotypes could be discriminated by using specific amplified band from either single or combined different primers. For example, the UBC811 primer is capable of detecting samples of gac 9 and 10 with DNA bands of 1,000 bp and 1,500 bp respectively (Figure 2). Gac 10 is distinguished by a 1,200 bp DNA band using the UBC853 primer (Figure 3). For UBC841 primer, there are 3 bands in which the $200 \mathrm{bp}$ band identifies gac 4, $300 \mathrm{bp}$ band identifies gac 5 samples and 1,700 bp band for sample identification gac 6 (Figure 4). The total numbers of DNA bands that can be used to distinguish $14 \mathrm{gac}$ samples in this study are presented in Table 4. This data emphasizes the potential of ISSR markers to identify specific organism and which have been reported in several studies such as distinguish Eucalyptus species (Balasaravanan et al. 2005); the invasive of lionfish (Labastida et al. 2015); sex in Phoenix dactylifera (Al-Ameri et al. 2016).
To calculate the genetic correlation coefficient and to construct the phylogenetic map, the ISSR results were encoded, and the phylogenetic tree was constructed using NTSYSpc version 2.1 software with the UPGMA clustering method in the SAHN program. The results showed that there was a significant variation in the coefficient of similarity between the samples: the highest correlation coefficient in the sample pair G12-G13 (0.80) and the lowest sample pair G05-G10 (0.45) (Table 5).

Table 3. Characteristics of DNA profiles generated in $14 \mathrm{gac}$ genotypes by using 10 ISSR primers

\begin{tabular}{llllll}
\hline Primer & SB & NPB & PPB $(\%)$ & PIC & RP \\
\hline UBC880 & 12 & 9 & 75.0 & 0.89 & 5.29 \\
UBC825 & 11 & 7 & 70.0 & 0.90 & 6.29 \\
UBC841 & 14 & 6 & 54.5 & 0.87 & 6.57 \\
UBC855 & 9 & 5 & 55.6 & 0.72 & 4.57 \\
UBC813 & 15 & 8 & 88.9 & 0.87 & 8.57 \\
UBC853 & 11 & 7 & 58.3 & 0.77 & 7.57 \\
UBC809 & 12 & 6 & 75.0 & 0.79 & 6.00 \\
UBC814 & 15 & 7 & 63.6 & 0.71 & 6.43 \\
UBC811 & 13 & 5 & 50,0 & 0.89 & 7.86 \\
UBC810 & 14 & 6 & 54.5 & 0.60 & 7.00 \\
Sum & 126 & 66 & - & - & - \\
Average & 12.6 & 6.6 & 66.2 & 0.80 & 6.61 \\
\hline
\end{tabular}

Note: SB: Scored bands; NPB: number of polymorphic bands; PPB: percentage of polymorphic bands; PIC: polymorphism information content; RP: resolving power.

Table 4. The ability to combine ISSR primers to identify gac samples

\begin{tabular}{llll}
\hline STT & Primer & Sample & $\begin{array}{c}\text { Approximate size of } \\
\text { candidate } \\
\text { amplification (bp) }\end{array}$ \\
\hline 1 & UBC841 & G04 & 200 \\
2 & UBC841 & G05 & 300 \\
3 & UBC841 & G06 & 1.700 \\
4 & UBC811 & G09 & 1.000 \\
5 & UBC811 & G10 & 1.500 \\
6 & UBC853 & G10 & 1.200 \\
7 & UBC814 & G11 & 400 \\
\hline
\end{tabular}

Table 5. Simple matching coefficients of similarity among 14 gac genotypes

\begin{tabular}{|c|c|c|c|c|c|c|c|c|c|c|c|c|c|c|}
\hline & G01 & G02 & G03 & G04 & G05 & G06 & G07 & G08 & G09 & G10 & G11 & G12 & G13 & G14 \\
\hline G01 & 1.00 & & & & & & & & & & & & & \\
\hline G02 & 0.54 & 1.00 & & & & & & & & & & & & \\
\hline G03 & 0.66 & 0.74 & 1.00 & & & & & & & & & & & \\
\hline G04 & 0.63 & 0.74 & 0.71 & 1.00 & & & & & & & & & & \\
\hline G05 & 0.54 & 0.56 & 0.52 & 0.63 & 1.00 & & & & & & & & & \\
\hline G06 & 0.66 & 0.61 & 0.57 & 0.67 & 0.56 & 1.00 & & & & & & & & \\
\hline G07 & 0.51 & 0.67 & 0.75 & 0.67 & 0.56 & 0.56 & 1.00 & & & & & & & \\
\hline G08 & 0.54 & 0.63 & 0.66 & 0.67 & 0.57 & 0.55 & 0.67 & 1.00 & & & & & & \\
\hline G09 & 0.56 & 0.63 & 0.66 & 0.69 & 0.54 & 0.61 & 0.67 & 0.75 & 1.00 & & & & & \\
\hline G10 & 0.52 & 0.56 & 0.56 & 0.56 & 0.46 & 0.52 & 0.52 & 0.62 & 0.59 & 1.00 & & & & \\
\hline G11 & 0.56 & 0.67 & 0.71 & 0.67 & 0.50 & 0.56 & 0.67 & 0.74 & 0.74 & 0.64 & 1.00 & & & \\
\hline G12 & 0.45 & 0.55 & 0.68 & 0.60 & 0.52 & 0.49 & 0.67 & 0.69 & 0.63 & 0.58 & 0.63 & 1.00 & & \\
\hline G13 & 0.45 & 0.64 & 0.70 & 0.62 & 0.53 & 0.52 & 0.71 & 0.67 & 0.58 & 0.58 & 0.71 & 0.79 & 1.00 & \\
\hline G14 & 0.58 & 0.60 & 0.68 & 0.70 & 0.58 & 0.59 & 0.66 & 0.64 & 0.69 & 0.56 & 0.63 & 0.65 & 0.62 & 1.00 \\
\hline
\end{tabular}




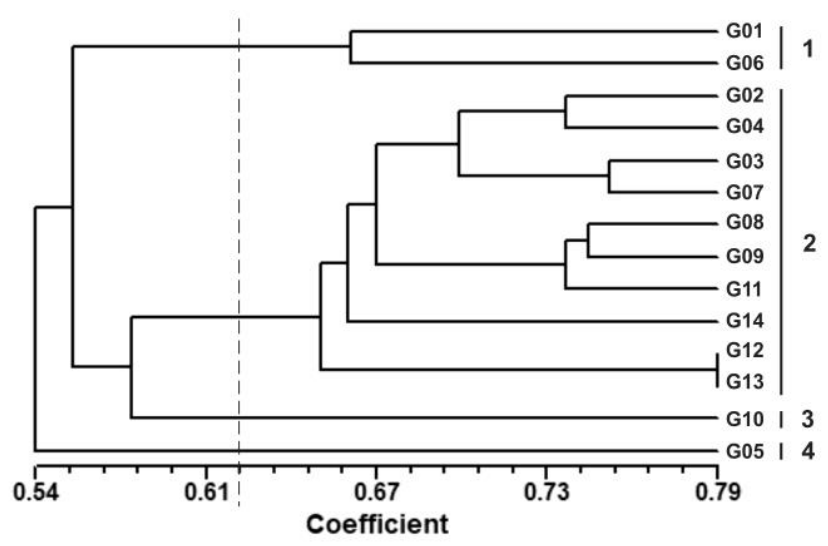

Figure 5. Phylogenetic tree generated by using 10 ISSR markers to show the genetic relativeness of 14 gac accessions collected in Southern Vietnam. The scale shown at the bottom is the measure of genetic similarity

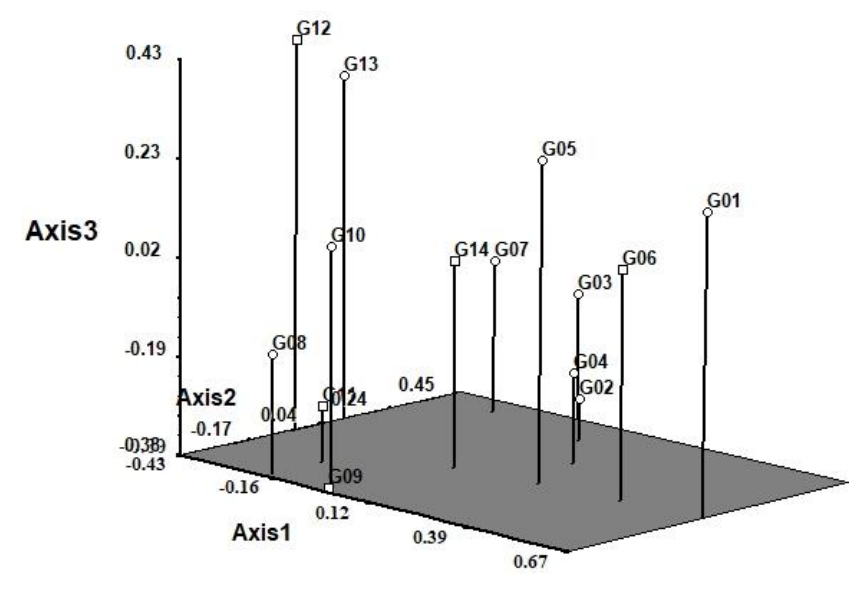

Figure 6. Three-dimensional plot of the principal coordinate (PCO) analysis of distance among 14 gac genotypes designated by codes given in Table 1 by using 10 ISSR markers

Based on the similarity matrix of 14 gac genotypes in Table 5, the phylogenetic tree was constructed and shown in Figure 5. Overall, the constructed phylogenetic tree shows a homology coefficient of studies gac genotypes ranging about 0.54 to 0.79 indicating the high level of genetic variation among genotypes studied. This result is similar to earlier study of Wimalasiri and colleagues when they studied the genetic diversity of different gac accession collected from Vietnam, Thailand, and Australia (Wimalasiri et al. 2016). The cut-off value of the phylogenetic tree was determined at 0.62 based on calculation method described by Jamshidi and Jamshidi (2011). Based on cut-off value, fourteen gac genotypes were divided into four major groups: Group 1, consisting of two samples: G01 (Chau Thanh, Tien Giang) and G06 (Thang Binh, Quang Nam). Group 2 occupied the majority with 10 samples including G02, G03 (Cai Be, Tien Giang), G07 (Mo Cay, Ben Tre), G12, G14 (Chau Thanh, Ben Tre),
G08 (Ham Thuan Nam, Binh Thuan), G11 (Cu Chi, Ho Chi Minh City), G13 (Duc Hoa, Long An), G04 (Bu Dang, Binh Phuoc), G09 (Thang Binh, Quang Nam). Meanwhile, group 3 and group 4 has only one accession in each group namely G10 (Thang Binh, Quang Nam) and G05 (Bu Dang, Binh Phuoc), respectively. Interestingly, G05 genotype was collected from Binh Phuoc province together with G04 genotypes but belonging to different groups. G05 genotype also shows the most genetic distant with the remaining 13 samples. This data revealed that the studied gac accessions were not grouped as geographical location where samples were collected. This could be due to the exchange of gac seeds or seedlings from different places which were mentioned by Pham et al. (2017). In addition, the introduction of gac varieties from neighboring countries such as Taiwan, Malaysia also contributes to the genetic difference of the gac varieties increase. Furthermore, the high diversity of collected samples in Vietnam could be owing to different reasons such as out-crossing system, the geographical difference. Different studies also reported the high genetic diversity could cause by the adaptation of plants to specific geographical areas such as wild barley (Dawson et al. 1993); chili (Albrecht et al. 2012); olive (Mousavi et al. 2014). The high genetic diversity of gac accessions collected in Southern Vietnam implies the diverse gene pool in this region. This genetic richness will be useful for gac breeding program in the future.

For better understanding about the grouping of $14 \mathrm{gac}$ genotypes, the principal coordinate analysis was further used to confirm the distribution frequencies of ISSR markers and shown in Figure 6. The plotting present $14.4 \%, 10.3 \%$ and $9.8 \%$ of the total variation for the first, second and third component, respectively. This data suggested that the variation was due to characteristics of specific genotype (Debnath et al. 2008). The highest similarity of G12 and G13 genotypes in Figure 5 is also confirmed where they are closely grouped by first axis. Similarly, group 1 consisting G01 and G06 genotypes are distributed together. However, the distribution of G05 genotype is relative changed, which was relocated and near to G02, G04, G06, G07, and G14 genotypes. Thus, the PCO analysis could reveal another level of separation of sample, and it could be benefit to use more than one types of analysis method.

In this study, by using 10 ISSR primers to analyze 14 gac samples collected in different provinces in Southern Vietnam we found that there is large genetic variation among studied genotypes. The collected samples were divided in 4 main groups showing the close relativeness of accessions in different places. We also found significant number of specific ISSR generated bands which could be further analyzed to use as specific markers to identify 14 specific gac accessions. The obtained results in this study will be important information which will be useful for plant breeders to use for several purposes such as classification, conservation, and gac breeding programs in Vietnam. In the future, the DNA bands could be continued to develop into SCAR markers to enhance the accuracy in breeding and conservation of gac in the research region. 


\section{ACKNOWLEDGEMENTS}

Authors are thankful to Faculty of Biotechnology, Ho Chi Minh City University of Food Industry, Vietnam for providing research facilities.

\section{REFERENCES}

Al-Ameri AA, Al-Qurainy F, Gaafar AZ, Khan S, Nadeem M. 2016. Molecular identification of sex in Phoenix dactylifera using inter simple sequence repeat markers. Biomed Res Int 2015: 5 pages. http: //dx.doi.org/10.1155/2016/4530846

Albrecht E, Zhang D, Mays AD, Saftner RA, Stommel JR. 2012. Genetic diversity in Capsicum baccatum is significantly influenced by its ecogeographical distribution. BMC Genet 13: 68 . https: //doi.org/10.1186/1471-2156-13-68

Anil Kumar VS, Sunila AV, Krishman R, Kurugan K. 2018. ISSR markers for comparative analysis of genetic variability in Solanum L. species of Southern Western Ghats of Kerala, South India. Eur J Pharm Med Res 5 (2): 293-300.

Balasaravanan T, Chezhian P, Kamalakannan R, Yasodha R, Marghese M, Gurumurthi K, Ghosh M. 2005. Identification of species-diagnostic ISSR marker for six Eucalyptus species. Silvae Genet 55 (3): 119 122. https: //doi.org/10.1515/sg-2006-0017

Bazzano LA, He J, Ogden LG, Loria CM, Vupputuri S, Myers L, Whelton PK. 2002. Fruit and vegetable intake and risk of cardiovascular disease in US adults: the first national health and nutrition examination survey epidemiologic follow-up study1-3. Am J Clin Nutr 76: 93-99. https: //doi.org/10.1093/ajcn/76.1.93

Behera TK, Singh AK, Staub JE. 2007. Comparative analysis of genetic diversity in Indian bitter gourd (Momordica charantia L.) using RAPD and ISSR markers for developing crop improvement strategies. Sci Hort 115: 209-217. https: //doi.org/10.1016/j.scienta.2007.08.013

Bootprom N, Songsri P, Suriharn B, Chareonsap P, Sanitchon J, Lertrat K. 2012. Molecular diversity among selected Momordica cochinchinensis (Lour.) Spreng accessions using RAPD markers. Sabrao J Breed Genet. 44 (2): 406-417.

Botstein D, White RL, Skolnick M, Davis RW. 1980. Construction of a genetic linkage map in man using restriction fragment length polymorphism. Am J Hum Genet 32: 314-331. https: //www ncbi.nlm nih gov/pmc/articles/PMC1686077/

Burke DS, Smidt CR, Vuong LT. 2005. Momordica cochinchinensis, Rosa roxburghii, wolfberry, and sea buckthorn-Highly nutritional fruit supported by tradition and science. Curr Top Nutraceut R 3 (4): 259 266. http: //www.nchpjournals.com/manuscript/uploads/article_897.pdf

Chesnokov YV, Artemyeva AM. 2015. Evaluation of the measure of polymorphism information of genetic diversity. Agric Biol 50 (5): 571-578.

Choudhary SK, Patel AK, Harish, Shekhawat S, Shekhawat NS. 2017. An improved micropropagation system, ex vitro rooting and validation of genetic homogeneity in wild female Momordica dioica: an underutilized nutraceutical vegetable crop. Physiol Mol Biol Plants 23 (3): 713-722. https: //doi.org/10.1007/s12298-017-0441-z

Debnath SC, Khanizadeh S, Jamieson AR, Kempler C. 2008. Inter Simple Sequence Repeat (ISSR) markers to assess genetic diversity and relatedness within strawberry genotypes. Can J Plant Sci 88 (2): 313 322. https: //doi.org/10.4141/cjps07088

Ibrahim KS, Gurusubramanian G, Zothansanga, Yadav RP, Senthi Kumar N, Pandian SK, Borah P, Mohan S. 2017. Bioinformatics-A student's Companion. Springer, Singapore. https: //doi.org/10.1007/978-981$10-1857-2$

Ishida BK, Turner C, Chapman MH, McKeon TA. 2004. Fatty acid and carotenoid composition of gac (Momordica cochinchinensis Spreng) fruit. J Agric Food Chem 52 (2): 274-279. https: //pubs.acs.org/doi/abs/10.1021/jf030616i

Jamshidi S, Jamshidi S. 2011. NTSYSpc 2.02e implementation in molecular biodata analysis (Clustering, screening and individua selection). IPCBEE 19: 165-169. http: //www.ipcbee.com/vol19/32 ICECS2011R30001.pdf

Kha TC, Nguyen MH, Roach PD, Parks SE, Stathopoulos C. 2012. Gac fruit: nutrient and phytochemical composition, and options for processing. Food Rev Int 29: 92-106. https: //doi.org/10.1080/87559129.2012.692141

Kubola J, Siriamornpun S. 2011. Phytochemicals and antioxidant activity of different fruit factions (peel, pulp, aril and seed) of Thai gac (Momordica cochinchinensis Spreng). Food Chem 127: 1138-1145. https: //doi.org/10.1016/j.foodchem.2011.01.115

Labastida E, Cobian D, Henaut Y, Garcia-Rivas MC, Chevalier PP, Machkour-M'Rabet S. 2015. The use of ISSR markers for species determination and a genetic study of the invasive lionfish in Guanahacabibe, Cuba. Lat Am J Aquat Res 43 (5): 1011-1018. https: //scielo.conicyt.cl/pdf/lajar/v43n5/art21.pdf

Mbwana J, Bölin I, Lyamuya E, Mhalu F, Lagergård T. 2006. Molecular characterization of Haemophilus ducreyi isolates from different geographical locations. J Clin Microbiol 44 (1): 132-137. https: //doi.org/10.1128/jcm.44.1.132-137.2006

Mousavi S, Hosseini Mazinani M, Arzani K, Ydollahi A, Pandolfi S, Baldoni L, Mariotti R. 2014. Molecular and morphological characterization of Golestan (Iran) olive ecotypes provides evidence for the presence of promising genotypes. Genet Resour Crop Evol 61: 775-785. https: //doi.org/10.1007/s10722-013-0071-4

Nguyen DT. 2014. Các kỹ thuật chỉ thị DNA trong nghiên cứu và chọn lọc thực vật. Tạp chí Sinh học. 36 (3): 265-294. http: //vjs.ac.vn/index.php/vjbio/article/viewFile/5974/5573

Nguyen TBL, Huynh DS, Pham DT, Bui CT. 2014. Genetic diversity of gac (Momordica cochinchinensis (Lour.) Spreng) collected in Central provinces in Vietnam by RADP. Journal of Agriculture and Extension 9: 18-22. (In Vietnamese)

Pham DT, Vo TH, Huynh VB, Bui MT, Bui CT. 2017. Genetic diversity of gac [Momordica cochinchinensis (Lour.) Spreng] accessions collected from Mekong delta of Vietnam revealed by RAPD markers. Aust J Crop Sci 11 (2): 206-211. https: //doi.org/10.21475/ajcs.17.11.02.p276

Prevost A, Wilkinson MJ. 1999. A new system of comparing PCR primers applied to ISSR fingerprinting of potato cultivars. Theor Appl Genet 98: 107-112. https: //doi.org/10.1007/s001220051046

Rahimi M, Maleki HH, Mortezavi M. 2017. Identification of informative markers of agronomic traits in different ecotypes of sand plantain (Plantago psyllium). Biologia 63 (4): 325-333. https: //doi.org/10.6001/biologija.v63i4.3607

Reddy MP, Sarla N, Siddiq EA. 2002. Inter-simple sequence repeat (ISSR) polymorphism and its application in plant breeding. Euphytica 128 (1): 9-17. https: //doi.org/10.1023/A: 1020691618797

Rohlf FJ. 2000. NTSYS-pc: Numerical taxonomy and multivariate analysis system, version 2.2. Exeter Software, Setauket, New York.

Shukla A, Sinha DP, Bhardwaj DR, Singh A, Kumar P, Singh M. 2017. Genetic Diversity among Four Momordica Species Using RAPD, SSR and ISSR Markers. Int $\mathrm{j}$ adv res 5: 1304-1319.

Singh AK, Behera TK, Chandel D, Sharma P, Singh NK. 2015. Assessing genetic relationships among bitter gourd (Momordica charantia L.) accessions using inter-simple sequence repeat (ISSR) markers. J Hortic Sci Biotechnol 82: 217-222. https: //doi.org/10.1080/14620316.2007.11512222

Tien PG, Kayama F, Konishi F, Tamemoto H, Kasono K, Hung NT, Kuroki M, Ishikawa SE, Van CN, Kawakami M. 2005. Inhibition of tumor growth and angiogenesis by water extract of $\mathrm{Gac}$ fruit (Momordica cochinchinensis Spreng.). Int J Oncol 26: 881-889. https: //doi.org/10.3892/ijo.26.4.881

Vuong TL, King JC. 2003. A method of preserving and testing the acceptability of gac fruit oil, a good source of $\beta$-carotene and essential fatty acids. Food Nutr Bull 24: 224-230. https: //doi.org/10.1177/156482650302400216

Vuong LT, Dueker SR, Murphy SP. 2002. Plasma $\beta$-carotene and retinol concentrations of children increase after a 30-d supplementation with the fruit Momordica cochinchinensis (gac). Clin Nutr 75: 872-879. https: //doi.org/10.1093/ajcn/75.5.872

Williams JG, Kubelik AR, Livak KJ, Rafalski JA, Tingey SV. 1990. DNA polymorphisms amplified by arbitrary primers are useful as genetic markers. Nucleic acids res 18 (22): 6531-6535. https: //doi.org/10.1093/nar/18.22.6531

Wimalasiri D, Piva T, Urban S, Huynh T. 2016. Morphological and genetic diversity of Momordica cochinchinensis (Cucurbitaceae) in Vietnam and Thailand. Genet Resour Crop Evol 63: 19-33. https: //doi.org/10.1007/s10722-015-0232-8

Zheng L, Zhang YM, Zhang Y, Li Z. 2014. Momordica cochinchinensis Seed Extracts Suppress Migration and Invasion of Human Breast Cancer ZR-75-30 Cells Via Down-regulating MMP-2 and MMP-9. Asian Pac J Cancer Prev 15: 1105-1110. https: //doi.org/10.7314/apjcp.2014.15.3.1105 